\title{
International Workshop on \\ "Equations of Convolution Type in Science and Technology" (Miskhor, Crimea, September, 2019)
}

Vladimir Lukianenko (V. I. Vernadsky Crimean Federal University, Simferopol, Russian Federation)

The international workshop on convolution-type equations ECTST-2019 was held in September 2019 (www. ectst.ru), dedicated to the 90th anniversary of the birth of Yuri Iosifovich Chersky. The conference was organised by the Crimean Federal University (Simferopol) and was held in the Park Hotel "Gloria", which is located in the territory of the former estate of the Naryshkin princes in the famous park "CHAIR" (Mishor, Yalta city district). This region not only boasts a unique climate, there are also many famous attractions along the southern coast of the Crimea: Lastochkino gnezdo, Vorontsov and Yusupov palaces, and the passenger cable car to the $\mathrm{Ai}$ Petri mountain.

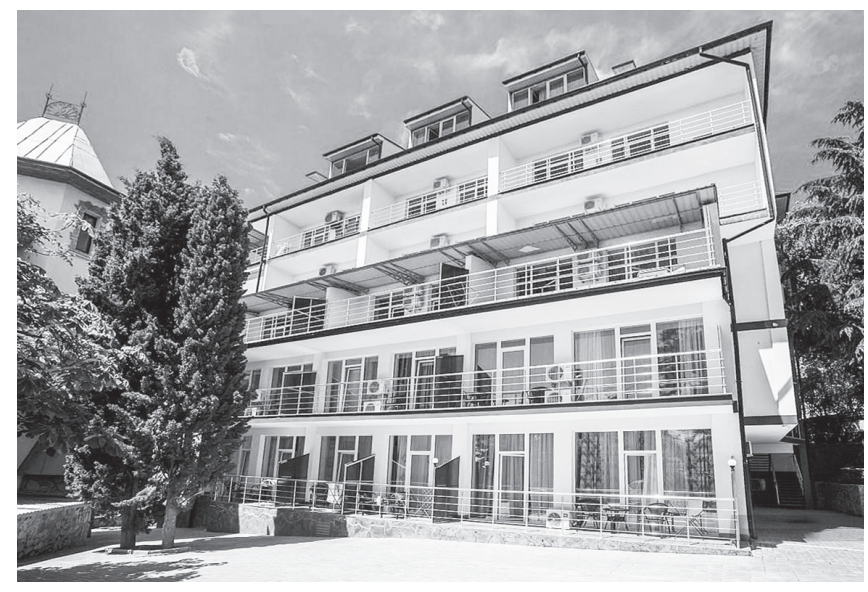

Park hotel "Gloria” (Mishor, Yalta city district).

The workshop was attended by more than 100 renowned and young scientists from Russia, Armenia, Germany, Mexico, Norway and France. Reports were presented (25 plenary, 36 poster and sectional) on a wide range of studies of pure and applied mathematics relating to the results and ideas of Yu.I. Chersky.

Yuri Iosifovich Chersky was born on 8 December 1929 in Kazan, USSR, to a family of medical doctors. In 1952 he graduated with honours from the Faculty of Mathematics of Kazan University. In his student years he was engaged in scientific work under the scientific supervision of Fyodor Dmitrievich Gakhov. After finishing post-graduate school in 1956, he defended his $\mathrm{PhD}$ thesis on the topic "Integral Equations of Convolution Type". After 1955 he successively became a lecturer, a senior lecturer, an associate professor of the Department

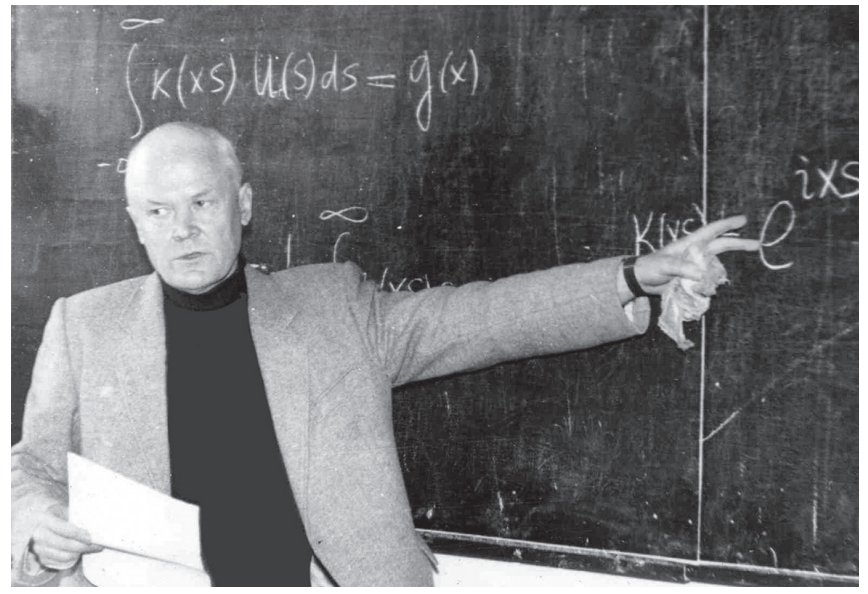

Yuri Iosifovich Chersky.

of Mathematical Analysis, and from 1961 to 1964 an associate professor of the Department of Computational Mathematics of the Rostov State University in the south of the Soviet Union. After defending his doctoral dissertation on "Integral equations of convolution type and some of their applications" in 1964, Yu.I. Chersky was invited to Odessa University, where he worked until 1972 as the head of the Department of Mathematical Physics. From 1972 to 1977 he was the head of the Department of Differential and Integral Equations of the Simferopol State University in Crimea, and from 1977 to 1983 the head of the Department of Integral Equations of the Institute of Applied Problems of Mathematics and Mechanics of the USSR Academy of Sciences in L'vov. In 1983 Yu.I. Chersky returned to Odessa as the head of the Department of Advanced Mathematics of the Odessa Institute for Marine Engineers. From 1995 he was a professor of the Odessa State Academy of Construction and Architecture, and the head of the Interuniversity Scientific Seminar.

The main areas of scientific interest to Yu.I. Chersky lie in the field of boundary value problems; the theory of analytic functions; and convolution-type equations and their applications, which cover a wide range of problems. His theoretical results are usually combined with appropriate applications.

Yu.I. Chersky is considered to be the first mathematician to reduce the boundary value problem of mathematical physics to the Riemann boundary value prob- 
lem on the real axis. He created an effective method of incomplete factorisation, developed an abstract theory of the Riemann problem and constructed a solution for convolution-type equations in the space of generalised functions.

Yu.I. Chersky researched new classes of convolutiontype equations. He introduced the smooth transition equation, its analogs and generalisations, and studied them in detail. He pioneered the formulation and solution of a number of extremal problems from the theory of analytic functions. The main results of Yu.I. Chersky are collected in two monographs.

Scientific research directions connected with the ideas of Yuri Iosifovich are intensively developed by many mathematical research centres and they are widely presented in the reports of the ECTST-2019 workshop. The conference topics covered a wide range of problems on convolution-type equations and boundary value problems in the theory of analytic functions; on differential equations, mathematical physics, geometry; on nonlinear convolution-type equations; but also on nonlinear dynamical systems, incorrect and inverse problems, optimisation methods, extremum problems and approximate solution methods.

Prof. A.F. Voronin delivered a plenary report on "Integral equations of convolution type on a finite interval and boundary value problems for analytic functions theory", Associate Prof. V.A. Lukyanenko - the report on "Smooth transition equations", Prof. S.N. Askhabov - the report on "Stability of solutions of nonlinear equations of convolution type in cones", Prof. Kh.A. Khachatryan (Armenia) - the report on "On some classes of nonlinear multidimensional integral equations of convolution type in the mathematical theory of the geographical spread of epidemics".

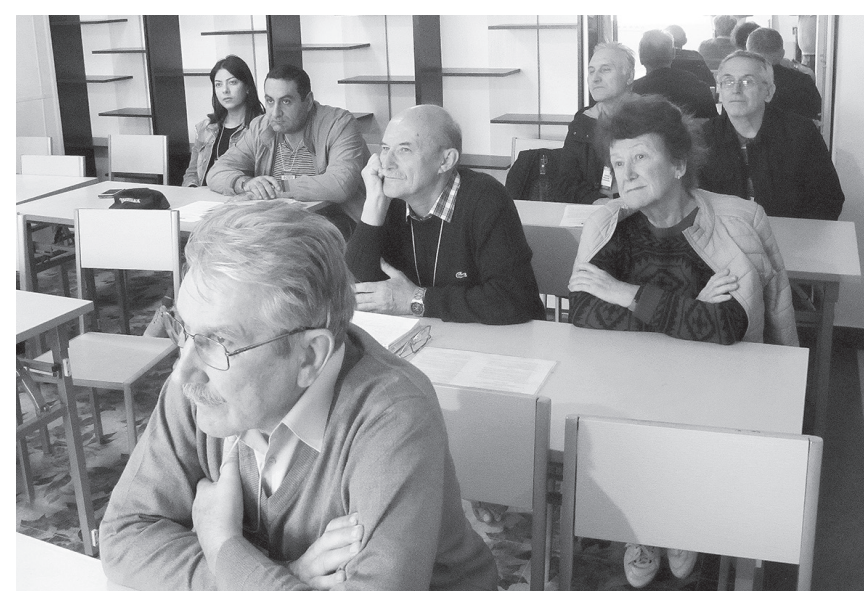

The section is working.

Interesting reports were also presented on differential equations and dynamical systems. Prof. V.A. Zagrebnov (France) spoke about solving the non-autonomous Cauchy problem in normed spaces; Prof. G.S. Osipenko about calculating the averaging spectrum over pseudotrajectories of dynamical systems; Prof. M.M. Shumafov and Prof. V.B. Tlyachev reported on the stability of random processes defined by the second-order differential equations; Prof. V.B. Vasiliev talked about elliptic boundary value problems; Prof. A.V. Kochergin about the escape velocity of cylindrical mapping orbits; and Prof. O.V. Anashkin presented a report on the algorithm for investigating the stability of a periodic pulse system in a critical regime.

Recent research on optimisation developed under the guidance of Prof. A.V. Gasnikov and associate Prof. F.S. Stonyakin (mirror descent method for conditional problems of convex optimization, Distributed and Parallel

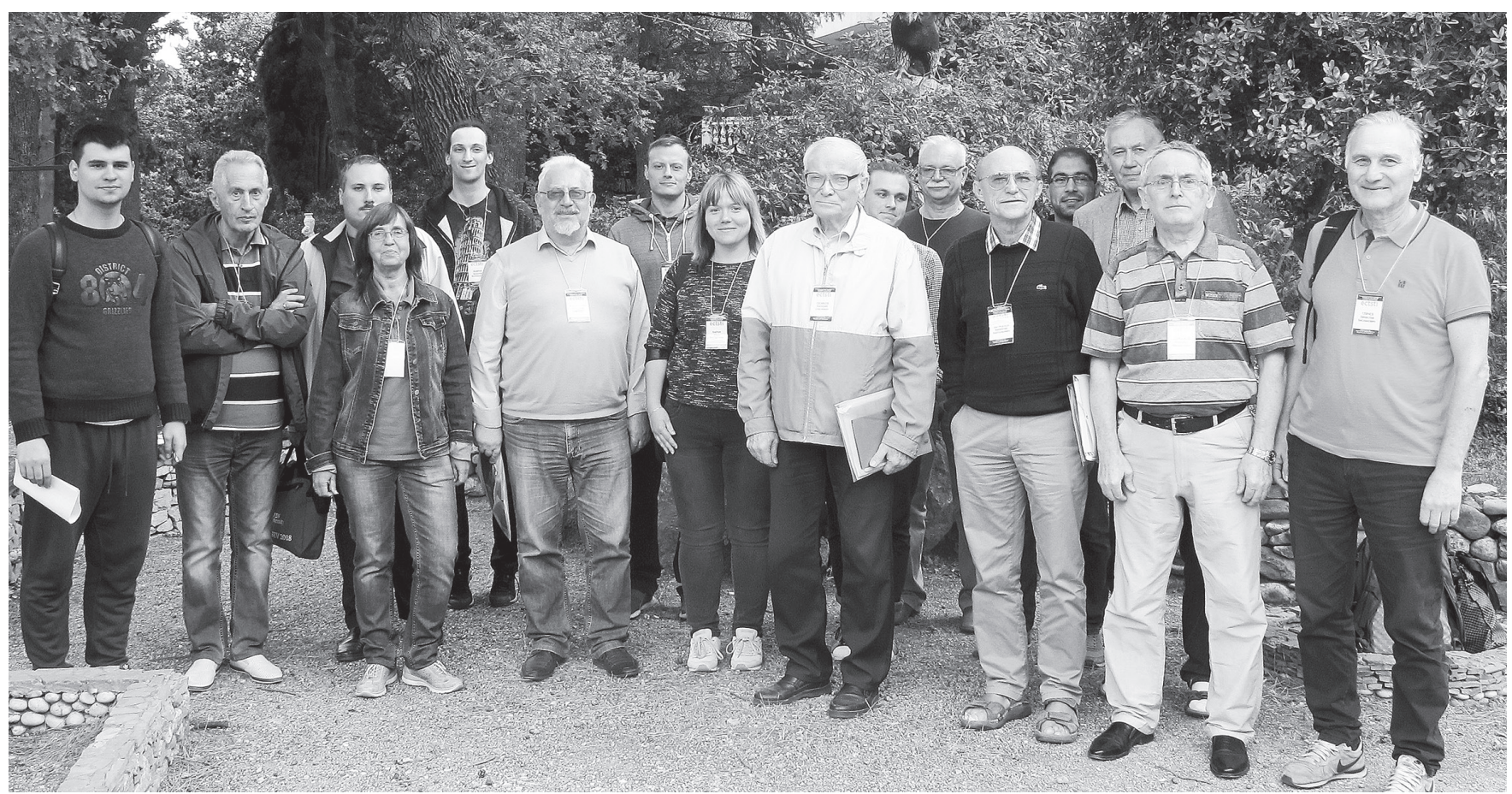

Participants of the ECTST-2019. 
Optimization) was also presented at the conference, as well as a report by D.V. Lemtyuzhnikova on suboptimal solutions of sparse discrete optimisation problems.

The workshop facilitated the exchange of views and scientific contacts in interdisciplinary research between teams of scientists from Simferopol, Novosibirsk, Moscow, Grozny, Rostov-on-Don, Nizhny Novgorod, Belgorod and mathematicians from Armenia, France, etc.

According to the participants, the workshop ECTST-2019 was held at a high scientific level; its results have been published in the Collection of Abstracts and in the issues 2-4 (2020) of the journal Dynamical Systems" (published by V.I. Vernadsky Crimean Federal University).

In September 2020, it is planned to continue discussions and exchange of scientific information at the workshop "Equations of convolution type, optimisation, forecasting" as part of the International Conference "Dynamic systems in Science and Technology" DSST2020 (www.dsst.su)

The organising committee has the pleasure of inviting readers of the EMS Newsletter to contribute and to participate in the International Conference DSST-2020, organised by the V.I. Vernadsky Crimean Federal University (Simferopol) with the participation of St. Petersburg State University, the Institute for Problems in Mechanical Engineering of the Russian Academy of
Sciences (St. Petersburg), the Trapeznikov Institute of Control Sciences of the Russian Academy of Sciences (Moscow)and the Sobolev Institute of Mathematics of the Siberian Branch of the Russian Academy of Sciences (Novosibirsk).

The topics of interest include, but are not limited to:

1. Mathematical theory of dynamical systems. Regular and chaotic dynamics.

2. Dynamical systems in mechanics.

3. Dynamical systems in control and information technologies.

4. Equation of Convolution type, optimisation, prediction.

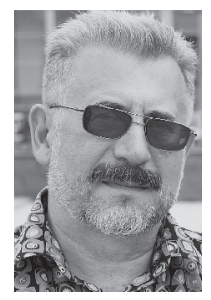

Vladimir Lukianenko [art-inf@yandex. ru,LukianenkoVA1@gmail.com] is an associate professor at the Department of Differential Equations and Geometry at V.I. Vernadsky Crimean Federal University in Simferopol, Republic of Crimea. His research interests include convolution type equations, boundary value problems, extreme and incorrect problems, nonlinear equations, mathematical modeling. He is chairman of the organising committee of the International workshop ECTST-2019. 